\title{
REVIEWS OF BOOKS
}

Common Skin Diseases. By A. C. Roxburgh, M.A., M.D., F.R.C.P. 7th Edition. $453+$ xxii pp. ; 184 illustrations and 8 plates in colour. H. K. Lewis \& Co., Ltd., London, 1944. 'Price 18s.

Skin diseases tend to become a problem of considerable importance during war-time. The infestations are spread readily during evacuation and through the herding together of communities in air-raid shelters; occupational hazards are increased; nutritional defects and nervous strain are factors often first recognized in skin reactions, and the conditions of Service life frequently lead to a breakdown in a man who is constitutionally liable to skin disease.

Skin disorders are a source of more prolonged absenteeism and loss of efficiency than is any other group of diseases ; it can therefore be claimed that a knowledge of dermatology is of first importance to every practitioner at the present time. This popular book is a clear introduction to the subject and gives an adequate outline of the more common skin reactions.

The illustrations are excellent and call for special recognition; many are original photographs taken by the author, who is able to obtain that contrast of light and shade which portrays the diseases in recognizable form. This is a most valuable adjunct to the study of dermatology and one which makes the book of special value to students and practitioners. This seventh edition has been fully revised and expanded. The useful diagnostic index is retained and enlarged.

Industrial dermatitis is included in the section on chemical irritants and its present importance is acknowledged by a revised outline of the problem. In this section forms of dermatitis from cosmetics, from resins in adhesive strapping and from rubber have now been included, and aetiology and treatment are considered.

The increased incidence of scabies has in certain areas reached alarming proportions and special legislation has been necessary ; much experimental work on the subject has been carried out by Kenneth Mellanby and our conception of the disease has been modified thereby. Roxburgh has rewritten the chapter on scabies in order to conform with these views but also indicates the practical application of them in civil practice. The essential treatment of contacts is made clear, whereas terminal disinfestation of bedding and clothing is said to be of little importance. Scabies is no longer stated to be a venereal disease-it appears to have ascended the social scale since Roxburgh's sixth edition! Treatment is very fully considered and many suitable applications are described; the various benzyl benzoate preparations are indicated and details of preparation are given. Other infestations which often occur in communal life are fully described.

Impetigo has been given careful consideration and the proposals for treatment modified; this section has been rewritten and enlarged. Sulphonamides for both local and internal treatment are mentioned with reserve and caution against the use of strong antiseptics is wisely stressed.

Preliminary impressions on the use of a penicillin ointment for local application are included ; cases of sycosis, impetigo, blepharitis, eczema and seborrhoea have been treated. It would appear that this substance may later prove to be of immense value in the treatment of certain local infective skin diseases, but that it is of little value in the presence of sensitized skin reactions such as eczema and seborrhoea.

The brief survey of avitaminosis has been corrected and rewritten. A consideration of immersion foot is included.

Throughout the book treatment has received fuller consideration and the restricted value of sulphonamides has achieved an extended recognition. Sulphonamide drug eruptions find brief mention in this edition; the incidence of these eruptions justifies more consideration, and the advice invariably to withhold the drug in any type of eruption would, if acted upon, lead to an increased sulphonamide sensitization of the population.

This book has already achieved considerable popularity, and the improvements which have been made in the new edition make it a valuable introduction to dermatology and a convenient reference book for students and general practitioners.

D. $\mathbf{E}$.

A Synopsis of Clinical Syphilis. By James Kirby Howles, M.D., M.M.S., 671 pp., illustrated. Henry Kimpton, London. Price 30s.

With the appearance of this new book, Professor Howles meets a war-time demand for an up-to-date and authoritative handbook on syphilis. The use of the word, synopsis, implies that here is a small volume containing a condensation of modern knowledge on this subject ; the book, however, belies its title, which is surely inappropriate for a well turned out and illustrated work containing some 580 pages of text, in which Professor Howles not only deals. fully and effectively with syphilis in its clinical aspects but also provides chapters on the epidemiology of the disease and on the organization of the syphilis clinic, including its social service aspects; in addition there is much sound and interesting information on the histopathology of the various lesions of syphilis.

In the sections on the cutaneous aspects, the primary, secondary and tertiary stages are fully described and amply illustrated with well chosen examples of the various manifestations. The great majority of the photographic illustrations are of lesions in coloured patients, and the

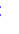
.

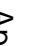
( N 
conditions thus portrayed are less easy of interpretation and memorization by the British student, who rarely sees any variety of disease in coloured people.

The arsphenamines and the methods of and the indications for their use receive satisfactory description. The author recommends neoarsphenamine as the arsenical of choice for the general practitioner, who, in the United States of America, treats the majority of the cases of syphilis. Arsphenamine is judged as being the most effective of these compounds but is classed by the author as not suitable for general use excepting the larger clinics. Mapharsen is cited as an excellent substitute for neoarsphenamine in patients who develop intolerance to the latter drug. For infants, whose toleration for arsenicals is always high, Professor Howles recommends sulpharsphenamine, but its use is not advised in adults on account of the high incidence in them of serious reactions. The various toxic effects that may accompany arsenical chemotherapy are clearly set out together with the appropriate prophylactic measures and treatment ; the blood dyscrasias, however, are dismissed in a rather cursory manner.

The standard treatment of syphilis, as laid down by the author in various courses of neoarsphenamine and bismuth compounds, is more closely in line with British and European schedules than with customary American methods. There seems to be an element of unnecessary delay in the recommendation that treatment be not commenced until the first visit following the definite diagnosis of syphilis-which may be as long as a week in Great Britain-at which time bismuth only is advised. Neoarsphenamine is not scheduled, in the author's course, to be given until another four days have elapsed; the reason for these delays, which are to be deprecated, is not stated. Such delay in the use of arsenicals, in the opinion of your reviewer, may in some cases be responsible for encouraging the transition from the sero-negative to the sero-positive phase in the early case of syphilis - with a graver prognosis.

A concise history of intensive arsenotherapy is included, beginning with the first trial of a five-day continuous infusion of neoarsphenamine by Chargin and his colleagues in 1933. The more recently used method of multiple injections of mapharsen is also discussed, together with its technique, complications and limitations. The use of mercury is described in a few pages and this metal is stated to be given in selected cases, but how the cases are selected is not mentioned.

In his discussion of the possibility of the infection of the ovum with Spirochaeta pallida, Professor Howles makes the startling comment that this spirochaete is five times the size of a spermatozoon. This, of course, is incorrect - unless a giant form of spirochaete has recently been evolved. The average length of $S$. pallida is 6-14 microns, whereas the length of the human spermatozoon is about 50 microns. A very brief survey of a mixed preparation of the two organisms under darkfield illumination will rapidly dispel any fallacies concerning the respective sizes of these two organisms, and incidentally should put an end to the persistently repeated statement in textbooks on syphilis, that the spermatozoon is too small to harbour a spirochaete within its structure.

This statement, which has been, apparently, copied from book to book for many years, is a good example of a chronic fallacy for which there has never been any reasonable foundation. Actually, both the head and the tail of the human spermatozoon are of ample capacity to harbour several spirochaetes. There is, however, little doubt that $S$. pallida would be unable to penetrate the particularly dense external covering of the human spermatozoon; in fact, it would be as likely to achieve penetration as would an attempt to perforate a bird's egg with a short piece of darning wool. It is conceivable that a spermatozoon from an infected man may carry $S$. pallida, but this spirochaete must have achieved penetration of the spermatozoon in its early stage as a spermatogonium or spermatocyte. It is, however, difficult to imagine an infected spermatocyte surviving and developing into a motile and functionally active spermatozoon.

The volume contains useful chapters on congenital syphilis, on syphilis in pregnancy and on the late effects of syphilis ; the treatment advocated is orthodox and thorough. In general, Professor Howles's new work is welcome as a lucid and accurate exposition of this subject; both the references and the index are extensive.

Prevention of Prostitution. A study of measures adopted or under consideration particularly with regard to minors. League of Nations Advisory Committee on Social Questions, Geneva. Ser. L.O.N. 143, IV.2. 182 pp. (For Great Britain, Allen and Unwin, London.) Price 6s.

This volume, which was almost completed and ready for publication in 1940, is now being issued in the series of League publications designed to be of present. or future value especially to authorities and organizations concerned with social reconstruction after the war. Following on its enquiry into the rehabilitation of adult prostitutes, the League of Nations Advisory Committee on Social Questions was led to consider measures for the prevention of prostitution. The former enquiry had shown that, however satisfactory the results that were obtained or that might be obtained by resort to measures of rehabilitation, such measures must inevitably be more difficult of application and less effective than preventive measures.

The present study, the publication of which is particularly opportune at the present time, differs from the enquiry into rehabilitation in that it is concerned chiefly with minors. For this there are two reasons. In the first place, prostitution can be prevented only by removing its causes, and these lie as much in heredity, environment and education as in the circumstances of adult life. Secondly, many girls become prostitutes before they are of full age.

The study was undertaken with the collaboration of the International Labour Office and of two experts who had taken part in the work of the League of Nations Advisory Committee. 